This is the author's final, peer-reviewed manuscript as accepted for publication. The publisher-formatted version may be available through the publisher's web site or your institution's library.

\title{
Role of House Flies in the Ecology of Enterococcus faecalis from Wastewater Treatment Facilities
}

C. W. Doud \& H. M. Scott \& L. Zurek

\section{How to cite this manuscript}

If you make reference to this version of the manuscript, use the following information:

Doud, C. W., Scott, H. M., \& Zurek, L. (2014). Role of House Flies in the Ecology of Enterococcus faecalis from Wastewater Treatment Facilities. Retrieved from http://krex.ksu.edu

\section{Published Version Information}

Citation: Doud, C. W., Scott, H. M., \& Zurek, L. (2014). Role of House Flies in the Ecology of Enterococcus faecalis from Wastewater Treatment Facilities. Microbial Ecology, 67(2), 380-391.

Copyright: @ Springer Science+Business Media New York 2013

Digital Object Identifier (DOI): 10.1007/s00248-013-0337-6

Publisher's Link: http://link.springer.com/article/10.1007/s00248-013-0337-6

This item was retrieved from the K-State Research Exchange (K-REx), the institutional repository of Kansas State University. K-REx is available at http://krex.ksu.edu 
For: $\quad$ Microbial Ecology

Role of house flies in the ecology of Enterococcus faecalis from wastewater treatment facilities

C. W. Doud ${ }^{a}$, H.M. Scott ${ }^{b}$ and L. Zurek ${ }^{a, b^{*}}$

${ }^{\mathrm{a}}$ Department of Entomology, Kansas State University, Manhattan, KS 66506

${ }^{b}$ Department of Diagnostic Medicine / Pathobiology, Kansas State University, Manhattan, KS 66506

${ }^{*}$ Corresponding author: Departments of Entomology and Diagnostic Medicine/Pathobiology

Kansas State University, Manhattan, KS 66506

Email: lzurek@ksu.edu phone: 7855324731 Fax: 7855326232

Running Head: $\quad$ House flies and E. faecalis in wastewater treatment facilities 


\section{Abstract}

Enterococci are important nosocomial pathogens with Enterococcus faecalis most commonly responsible for human infections. In this study, we used several measures to test the hypothesis that house flies, Musca domestica (L.), acquire and disseminate antibiotic resistant and potentially virulent $E$. faecalis from wastewater treatment facilities (WWTF) to the surrounding urban environment. House flies and sludge from four WWTF (1-4) as well as house flies from three urban sites close to WWTF-1 were collected and cultured for enterococci. Enterococci were identified, quantified, screened for antibiotic resistance and virulence traits, and assessed for clonality. Of the eleven antibiotics tested, E. faecalis was most commonly resistant to tetracycline, doxycycline, streptomycin, gentamicin and erythromycin and these traits were intra-species horizontally transferrable by in vitro conjugation. Profiles of $E$. faecalis (prevalence, antibiotic resistance, and virulence traits) from each of WWTF sludge and associated house flies were similar, indicating that flies successfully acquired these bacteria from this substrate. The greatest number of $E$. faecalis with antibiotic resistance and virulence factors (i.e., gelatinase, cytolysin, enterococcus surface protein, and aggregation substance) originated from WWTF-1 that processed meat waste from a nearby commercial meat processing plant, suggesting an agricultural rather than human clinical source of these isolates. E. faecalis from house flies collected from three sites 0.7 - $1.5 \mathrm{~km}$ away from WWTF-1 were also similar in their antibiotic resistance profiles; however, antibiotic resistance was significantly less frequent. Clonal diversity assessment using pulsed-field gel electrophoresis revealed the same clones of $E$. faecalis from sludge and house flies from WWTF-1 but not from the three urban sites close to WWTF-1. This study demonstrates that house flies acquire antibiotic resistant enterococci from WWTF and potentially disseminate them to the surrounding environment.

KEY WORDS: E. faecalis, house flies, antibiotic resistance, wastewater treatment facilities 


\section{Introduction}

The burden posed by antibiotic resistant (AR) bacteria is increasing worldwide [29, 39]. The rise of AR pathogens such as methicillin-resistant Staphylococcus aureus (MRSA) and vancomycin-resistant enterococci (VRE) has increased morbidity and mortality associated with bacterial infections and made effective treatment a significant challenge $[5,59,61]$.

Enterococci are Gram-positive, lactic acid bacteria and their primary niche is the digestive tract of animals, including humans. Enterococcus faecalis and E. faecium are two of the most prevalent enterococcal species in the human gastrointestinal tract $[6,20,21,53,62]$. Over the past few decades enterococci have emerged as the third most common nosocomial pathogen [6,21], and among enterococci, E. faecalis is responsible for the majority of hospital-associated infections [32, 68]. Antibiotic resistance of enterococci has been reported to every major class of antibiotics [34, 40]. A number of virulence factors associated with clinically significant enterococci aid in avoidance of host immune responses and/or help breakdown of host tissues [20]. In addition to being opportunistic pathogens, enterococci are also reservoirs of antibiotic resistance genes, thus playing an important role in AR gene ecology. Antibiotic resistance genes have been reported to transfer from enterococci to other bacteria such as Staphylococcus aureus [34, 66].

The house fly, Musca domestica (L.) is the most common fly species in the family Muscidae and is distributed worldwide. House flies are a significant nuisance pest due to their large populations and synanthropic nature. Additionally, house flies are recognized as an efficient mechanical vector of a number of parasites and pathogens including protists, viruses, fungi, and bacteria [23, 25].

Several studies have specifically focused on the association of $M$. domestica and enterococci in animal agriculture environments including poultry [24], swine [1], and cattle [11, 41]. Each of these studies provided evidence that house flies acquire AR and potentially virulent enterococci from the animal manure. Previously, we analyzed the digestive tracts of $M$. domestica for enterococci at five fast-food restaurants in northeastern Kansas and found AR enterococci very common [44]. In a follow-up study we found that food from the same restaurants was commonly contaminated with AR enterococci and contamination was positively correlated to seasonal house fly activity [43]. In a laboratory based study we showed that house flies can readily contaminate ready-to-eat food with enterococci [42]. These studies 
provided both direct and indirect evidence that animal agriculture (i.e., poultry, swine, cattle operations) can be a source of AR enterococci and that house flies are a likely vector.

Another potential source of AR enterococci in M. domestica is human fecal material; especially feces of the hospital origin. Though it is unlikely that flies gain access to hospitals or health clinics in developed countries, sewage waste from these facilities can be accessed as a potential point source at municipal wastewater treatment plants where wastewater is processed from multiple sources including household, healthcare, and industrial sites.

A 2007 report from the North East Biosolids and Residuals Association (NEBRA) estimated that there were approximately 17,000 operating wastewater treatment facilities (WWTF) in the USA [52]. Waste received from environments under significant antibiotic pressure, such as hospitals, consistently contains a greater proportion of singly and multiple drug-resistant bacteria $[9,22,26,28,38,60]$ and $A R$ enterococci are commonly recovered from sewage $[2,8,9,28,38,47,51,55]$. House flies and other filth flies often have direct and unhindered access to many steps in the waste processing flow and therefore may acquire bacteria associated with the waste. Once house flies disperse from the WWTF, they may disseminate microbes to other areas, with potential impacts on human health. In this study, we investigated whether house flies acquire antibiotic resistant and potentially virulent $E$. faecalis from WWTF and disseminate them to the surrounding urban environment.

\section{Methods}

Study duration and sites

Samples of sludge and flies were collected during 25 visits to four WWTF (1-4) over three years. The wastewater operations utilized the activated sludge technique for processing liquid waste with forced aeration during primary treatment $[12,33]$. Criteria for sludge collection at the facilities involved identifying locations that offered access to house flies and where flies were most visually abundant. The term sludge represents here three specific sources of solids: bar screening waste, insoluble grit, and treated biosolids $[7,12,33]$.

WWTF-1 served a northeast Kansas community of 21,000 and received approximately 2.8 million liters of waste daily from two sources; residential sewage (95,000 liters) and industrial waste from a 
nearby commercial sausage plant (1.9 million liters) but no waste from hospitals. The sausage plant was a $17,000 \mathrm{~m}^{2}$ facility that produced ready-to-eat cooked sausage. Waste from this facility arrived through a dedicated line and was initially kept separated from the sewage. The solids of the industrial waste (primarily meat remains) were separated and temporarily stored in open containers (garbage dumpsters) and were removed weekly. Due to the abundance of flies at this source, the stored meat waste solids were the focus of sludge and house fly sampling at WWTF-1.

WWTF-2 served the same community of 21,000 and processed approximately 6.8 million liters of waste daily, including influent from a small community hospital with a four-bed ICU. Sludge and biosolids were digested and stored in closed containers that limited fly access. Flies and sludge from this site were collected at the initial bar screen and the grit removal stations.

WWTF-3 served a community of 53,000 and received 20.8 million liters of waste daily, including waste from a medium-sized hospital with an eight-bed ICU and a four-bed intermediate ICU. Flies and solids were sampled from three locations: the bar screen, grit removal station, and on the margins of the secondary clarifier (where floating scum was removed and consolidated).

WWFT-4 received 1.7 million liters of waste daily from a community of 4,400 . The community was served by a small medical facility of 25 beds with no ICU. Sludge was processed using aerobic digestion [7] for approximately 20 days, after which it was dried by use of a belt press and stored in an open field onsite. Sludge and solids from Site 4 were collected at the bar screen and from treated biosolids that were stored onsite.

All study sites were sampled equally with regard to house fly/sludge samples and isolates characterized during the first year to estimate the overall fly activity, enterococcal diversity and antibiotic resistance/virulence. Based on the results of WWTF-1, including the antibiotic resistance profiles of enterococci, the abundance of flies and the unique source of industrial waste received, this site became the focus of more intensive sampling in year 2 , and was exclusively sampled in year 3 . Over the course of the study, 89 sludge samples were taken (41 from WWTF-1, 15 from WWTF-2, 14 from WWTF-3 and 19 from WWTF-4) and 276 house flies sampled (83 from WWTF-1, 84 from offsite of WWTF-1, 28 from WWTF-2, 43 from WWTF-3 and 38 from WWTF-4) (Table 1). 
Three offsite locations were selected near WWTF-1: Sites were selected based on the greatest potential for human/fly contact: at a recreational vehicle (RV) park located approximately $0.7 \mathrm{~km}$ (housing approximately 30 residents), a fast-food restaurant located approximately $1 \mathrm{~km}$, and a 600 unit apartment complex apartment complex with approximately 1200 tenants, located 1.5 - $2 \mathrm{~km}$ from WWTF-1. No offsite sampling occurred at WWTF 2-4.

Isolation and identification of enterococci from sludge and house flies

House flies were collected with a sweep net, transferred to a self-sealing plastic bag and placed on ice for transport to the laboratory. Sludge samples were placed into sterile containers and set on ice for approximately $2 \mathrm{~h}$. All samples were processed immediately upon arrival at the laboratory. One gram of sludge was homogenized in $10 \mathrm{ml}$ of sterile phosphate buffered saline (PBS). House flies were surface sterilized as described by Zurek et al. [74] and homogenized individually in $1 \mathrm{ml}$ of sterile PBS. All sludge and fly samples were 1/10 serially diluted and drop plated on m-Enterococcus ( $m$-Ent) agar (Difco, Franklin Lakes, $\mathrm{NJ})$. Plates were incubated at $37^{\circ} \mathrm{C}$ for $48 \mathrm{~h}$ upon which the concentration of enterococci was determined by counting colony forming units (CFU). Up to five dark purple colored colonies, presumptive of the Enterococcus genus, were picked from each sample for confirmation testing. To confirm the Enterococcus genus, an esculin hydrolysis test was utilized [57]. All positive isolates were transferred into TSBA $(0.3 \%$ agar $)$ in $2.0 \mathrm{ml}$ vials and stocked at $8^{\circ} \mathrm{C}$.

E. faecalis and E. faecium were identified by multiplex PCR with primers for D-alanineD-alanine ligase $(d d l)$ specific for each species [18, 35]. Enterococcus faecalis V583 and E. faecium ATCC 19434 were used as positive controls. Isolates not identified as E. faecalis or E. faecium during the 2008 season were instead identified by sequencing the superoxide dismutase gene (sodA) [56]. The

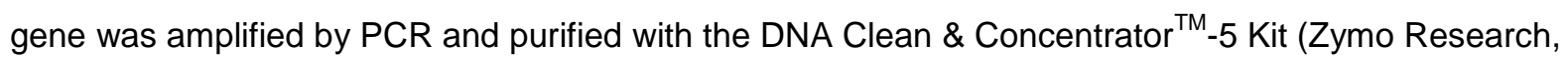
Irvine, CA). DNA samples were then sequenced at the Genome Core Facility (University of California, Riverside) using the same primers. Sequences were manually inspected in the CodonCode 4.1.1. (CodonCode Corp., Centerville, MA) and identified by BLAST search in the NCBI GenBank database (http://blast.ncbi.nlm.nih.gov). For years 2 and 3, only E. faecalis and E. faecium were identified (via species specific PCR as described above) and characterized due to the dominance of these two species and their clinical significance. 


\section{Antibiotic resistance}

All identified isolates were assessed for antibiotic susceptibility. Screening for nine antibiotics was done by disk diffusion technique on Mueller-Hinton agar (Difco, Franklin Lakes, NJ) using the protocols of the Clinical and Laboratory Standards Institute [13]. The eight antibiotics tested were doxycycline $(30 \mu \mathrm{g})$, gentamicin $(120 \mu \mathrm{g})$, erythromycin $(15 \mu \mathrm{g} /)$, ampicillin $(10 \mu \mathrm{g})$, ciprofloxacin $(5 \mu \mathrm{g})$, vancomycin $(30 \mu \mathrm{g})$, nitrofuratoin $(300 \mu \mathrm{g})$, and tigecycline $(15 \mu \mathrm{g})$. The agar dilution technique was used to determine resistance to streptomycin $(2 \mathrm{~g} / \mathrm{L})$, tetracycline $(16 \mathrm{mg} / \mathrm{L})$, and linezolid $(8 \mathrm{mg} / \mathrm{L})$ added to Mueller-Hinton agar. Quality controls were E. faecalis OGIRF, E. faecalis OG1SSP, and E. faecalis 4131.

\section{Virulence}

E. faecalis were screened with multiplex PCR for the following virulence genes: gelE (gelatinase activity), cylA (cytolysin, hemolytic activity), esp (enterococcal surface protein), and asa1 (aggregation substance) [69]. E. faecalis MMH 594 was used as a positive control for all genes. Gelatinase activity was determined on Todd Hewitt Broth (THB) (Difco, Franklin Lakes, NJ) agar plates with 1.5\% dry skim milk powder [41]. Isolates were streaked on TSB plates and grown overnight at $37^{\circ} \mathrm{C}$ and then spotted onto the THB/skim milk plates. Following incubation at $37^{\circ} \mathrm{C}$ for $24 \mathrm{~h}$, plates were examined for a clearance zone to assess gelatinase activity. Isolates were characterized as either gelatinase negative (no clearance), weak gelatinase (some clearance) or strong gelatinase (wide area of clearance). Cytolysin gene expression was evaluated as described by Ahmad et al. [1]. Isolates were streaked on Columbia blood agar (Difco, Franklin Lakes, $\mathrm{NJ}$ ) with $5 \%$ human blood and incubated at $37^{\circ} \mathrm{C}$ for $24 \mathrm{~h}$. Hemolytic activity was assessed by measuring the clearing zone around colonies. A large clearance zone was scored as $\beta$-hemolysis and considered positive for cytolysin gene expression. E. faecalis OG1X:pAM1 was used as a positive control for $\beta$-hemolysis. Enterococcal aggregation substance was screened phenotypically by the clumping assay for all E. faecalis strains from WWTF-1 positive for the asa1 gene [17]. Briefly, E. faecalis $\mathrm{JH} 2-2$ was used for cCF10 peptide formation. THB was used to grow E. faecalis $\mathrm{JH} 2-2$ and incubated at $37^{\circ} \mathrm{C}$ for $18 \mathrm{~h}$. The pheromone peptide in the supernatant was collected by centrifugation (10,000 rcf for $10 \mathrm{~min})$ and then sterilized by autoclaving for $15 \mathrm{~min}$. E. faecalis isolates were cultured in THB broth for $18 \mathrm{~h}$ at $37^{\circ} \mathrm{C}$ and $1 \mathrm{ml}$ E. faecalis $\mathrm{JH} 2-2$ supernatant was added to 
each culture and incubated at $37^{\circ} \mathrm{C}$ overnight in a shaker incubator. After the incubation period, isolates were considered positive if clumping or aggregations of cells were visually observed. E. faecalis OG1RF (pCF10) was used as a positive control and E. faecalis OG1SSP a negative control with every batch of isolates tested.

Horizontal gene transfer

Conjugation assays were performed for eight multiple antibiotic resistant strains of $E$. faecalis to test for horizontal transfer of resistance determinants. Selection of antibiotics used in brain heart infusion broth $(\mathrm{BHI})$ agar plates was done based on the resistance pattern of each of the donor and recipient strains. Concentrations of antibiotics added to $\mathrm{BHI}$ agar are listed below. The recipient strain for transfer of gentamicin $(500 \mathrm{mg} / \mathrm{L})$, tetracycline $(16 \mathrm{mg} / \mathrm{L})$, doxycycline $(0.5 \mathrm{mg} / \mathrm{L})$ and erythromycin $(32 \mathrm{mg} / \mathrm{L})$ resistance was E. faecalis OG1SSP using the marker antibiotic spectinomycin (250 mg/L). Due to crossresistance with spectinomycin, the recipient for streptomycin $(2 \mathrm{~g} / \mathrm{L})$ resistance was a wild-type isolate $E$. faecalis 41-31 with a linezolid marker ( $8 \mathrm{mg} / \mathrm{L})$. Conjugation frequencies were determined both by filter mating and broth mating assays using donor and recipient cultures grown overnight at $37^{\circ} \mathrm{C}$ in $\mathrm{BHI}$ broth as described previously $[16,67]$. Tansconjugate rate was calculated by dividing the transconjugate CFU count by the donor CFU count (T/D).

Pulsed-field gel electrophoresis (PFGE)

PFGE was performed to genotype isolates from WWTF sludge and house flies following the protocol of Amachawadi et al. [4] with the following modifications: Agarose plugs were restriction digested with $40 \mathrm{U}$ of $\mathrm{Apal}$ (Promega) for $4 \mathrm{~h}$ at $37^{\circ} \mathrm{C}$. The digested plugs were run on to a $1.0 \%$ SeaKem Gold Agarose (Lonza) gel using CHEF Mapper (Bio-Rad) with initial pulse time for $1 \mathrm{~s}$ and final time for $20 \mathrm{~s}$ at $200 \mathrm{~V}$ for $21 \mathrm{~h}$. Cluster analysis was performed with BioNumerics (Applied Maths) by using the bandbased Dice correlation coefficient and the unweighted pair group mathematical average algorithm (UPGMA). E. faecium ATCC 19434 was used as the reference strain.

\section{Statistical analysis}

Statistical analysis was performed to evaluate differences in prevalence of antibiotic resistance and virulence genotypic profiles among $E$. faecalis based on wastewater treatment site (WWTF 1-4) and isolate source (sludge, onsite house flies, offsite house flies). A mixed-effect logistic regression model 
was used to test for differences in attributes such as resistance among E. faecalis from the four wastewater treatment sites and three sources while accounting for the within cluster dependence effect both by sample and source [70].

The antibiotic resistance profiles among E. faecalis from WWTF-1 were then compared to the combined results from WWTF 2, 3, 4 due to the fundamental differences in the waste received (industrial meat waste at WWTF-1 versus sewage at WWTF-2,3,4). A mixed-effect logistic regression model used site (WWTF-1 vs. 2,3,4) and isolate source (sludge, onsite house flies) as fixed effects, variance components due to repeated observations within site and flies as random effects, and isolate resistance/susceptibility to tetracycline, doxycycline, streptomycin, gentamicin, and erythromycin as the binary response variables $[15,70]$.

Antibiotic resistance prevalence among $E$. faecalis at WWTF-1 was further subanalyzed by adding a third source, offsite house flies, to the two already mentioned. The regression model in this analysis used source (sludge, onsite house flies, offsite house flies) as the fixed effect, variance component due to repeated observations within flies as the sole random effect, and isolate resistance/susceptibility to tetracycline, doxycycline, streptomycin, gentamicin, and erythromycin as the binary response variables.

The virulence genotype of $E$. faecalis at WWTF-1 was also analyzed using a mixed-effect logistic regression with source (sludge, onsite house flies, offsite house flies) as the fixed effect and presence/absence of gelE, asa1, esp and $c y / A$ as the response variables [15, 70]. Significance level for all analyses was $P<0.05$.

\section{Results}

Prevalence, quantification and identification of enterococci

During the first year of the study, all enterococcal isolates chosen from selective media plates were identified to species in order to appraise the diversity in this environment. Two hundred twenty five enterococci were identified consisting of 11 species, of which the majority (76.9\%) was either E. faecalis $(60.4 \%)$ or E. faecium (16.4\%) (Fig. S1). The other species identified were E. flavescens, E. 
casseliflavus, E. gallinarum, E. malodoratus, E. sulfureus, E. durans, E. avium, E. moraviensis, and E. hirae (Fig. S1).

\section{Antibiotic resistance of $\underline{E}$. faecalis}

E. faecalis were tested for resistance to 11 antibiotics. Isolates were most commonly resistant to one or more of five antibiotics: tetracycline, doxycycline, streptomycin, gentamicin and erythromycin, with tetracycline resistance the most frequent (Fig. 1). None of the E. faecalis isolates were resistant to ampicillin, vancomycin, linezolid, and tigecycline (Fig. 1). E. faecalis from WWTF-1 consistently expressed significantly higher resistance than those from WWTF 2-4 (erythromycin and streptomycin, $P<$ 0.01; tetracycline, doxycycline and gentamicin, $P<0.0001$ ) (Fig. 1).

The pattern of multiple antibiotic resistances from WWTF-1 corresponded well among E. faecalis isolates from sludge and onsite house flies and less among isolates from offsite house flies (Table 2). For example, co-resistance to the combination of tetracycline, doxycycline and gentamicin was observed among sludge, onsite $\mathrm{HF}$ and offsite $\mathrm{HF}$ at $15.9 \%, 12.5 \%$ and $1.0 \%$, respectively, while co-resistance to the five antibiotics tetracycline, doxycycline, erythromycin, streptomycin and gentamicin occurred at $25.0 \%, 20.0 \%$ and $1.0 \%$, respectively (Table 2 ).

Resistance profiles were compared between WWTF-1 E. faecalis and the combined patterns of WWTF 2-4, which provided a contrast of $E$. faecalis from WWTF-1 industrial meat waste versus human sewage at WWTF 2-4. The prevalence of resistance was significantly different for tetracycline $(P<$ 0.0001), erythromycin $(P<0.01)$, streptomycin $(P<0.01)$ and gentamycin $(P<0.0001)$ but did not differ for doxycycline $(P>0.05)$.

\section{Horizontal transfer of antibiotic resistance traits}

Eight multiple-resistant E. faecalis isolates from six WWTF-1 house flies (three from offsite flies, five from onsite flies) were selected for AR gene horizontal transfer assays using broth and filter mating for gentamicin, streptomycin, tetracycline, doxycycline and erythromycin resistance traits. All of the isolates tested resulted in transconjugates to at least one of the antibiotics at transconjugate/donor (T/D) rates ranging from $2.9 \times 10^{-8}$ to $7.3 \times 10^{-3}$ (Table 3 ). Three of the eight isolates transferred all resistances tested in broth and/or filter assays at T/D rates of $6.9 \times 10^{-7}$ to $7.3 \times 10^{-3}$. During broth mating, streptomycin resistance was transferred most often $(5 / 8,62 \%)$ at rates from $1.1 \times 10^{-6}$ to $5.5 \times 10^{-3}$. 
During filter mating assays, all isolates tested (8/8) transferred doxycycline resistance at rates from $8.5 \mathrm{x}$ $10^{-8}$ to $7.3 \times 10^{-3}$ (Table 3 ).

\section{Enterococcus faecalis virulence traits}

All E. faecalis from WWTF-1 were tested genotypically with multiplex PCR for gelE, asa1, esp, and $c y / A$. Virulence phenotypic tests were performed for gelatinase, aggregation substance and cytolysin activity. The virulence gene, gelE was commonly detected from all three sources (sludge, onsite and offsite HF) followed by asa1, and cylA, while esp was the least common trait (Table 4). When compared statistically, the overall prevalence of the genes among E. faecalis from the three sources did not differ for gelE. The asa1 prevalence was not different from sludge and onsite house flies; however, asa1 prevalence was lower $(P<0.01)$ comparing offsite HF to sludge and onsite HF. The prevalence of esp was not different from sludge and onsite HF but was higher $(P<0.05)$ from offsite HF. Finally, cylA prevalence did not differ among the three sources (Table 4).

Among the gelE isolates, the majority exhibited the strong gelatinase phenotype (Table 4). Among asa1 positive isolates, $11.7 \%$ from sludge, $16.7 \%$ from onsite $\mathrm{HF}$ and $2.7 \%$ from offsite $\mathrm{HF}$ exhibited the clumping phenotype (Table 4). Among cylA positive isolates, 5.9\% from sludge, $12.5 \%$ from onsite HF and $30.0 \%$ from offsite HF exhibited $\beta$-hemolysis (Table 4).

For WWTF 2-4, only gelatinase phenotypic screening was performed. With the exception of sludge isolates from WWTF-2, the majority of isolates from both sources (sludge or house flies) exhibited either the strong or weak gelatinase phenotype (data not shown). For all locations, the strong gelatinase phenotype was most commonly observed over weak gelatinase, ranging from $22.6 \%$ of sludge isolates at WWTF-2 to $84.6 \%$ of sludge isolates at WWTF-4.

\section{Clonality of E. faecalis from and around WWTF-1}

Isolates from WWTF-1 were genotyped using pulsed-field gel electrophoresis (PFGE) to determine their clonality within and among the three sources. From the second year, $40 \mathrm{E}$. faecalis were genotyped. Selection of isolates was based on identifying groups with similar antibiotic resistant and virulence profiles across the three sources. Overall genotypic diversity was high both among and within the sources (majority between $65-85 \%$ similarity) (Fig. S2). One clone was detected from two separate sludge samples collected one week apart. Another two clones from the same sludge sample were similar 
(> 95\%); however, no other similar genotypes were identified. Further, there was little to no apparent grouping of isolates by source (Fig. S2).

In the third year, efforts were made to increase the likelihood of detecting similar strains by genotyping isolates collected on the same day. Two sampling dates were selected where eight or more isolates were available from each of the three sources resulting in a group of $51 \mathrm{E}$. faecalis isolates. A high level of genotypic variation was observed among the isolates; however, three clonal matches involving eight isolates were detected among bacteria recovered from sludge and onsite house flies (Fig. 2) but none from the offsite house flies.

\section{Discussion}

Wastewater treatment facilities play a significant role in the ecology of many microbes $[47,63]$. Due to easy access of house flies to WWTF, these insects may be involved in dissemination of bacteria, including pathogens and antibiotic resistant strains to the surrounding urban environment. The focus of this study was to employ multiple phenotypic and genotypic approaches to characterize enterococci from wastewater sludge and house flies collected directly at WWTF and from the surrounding urban sites.

During the first year of the study, all enterococcal isolates from the selective medium were identified to the species level. Due to the dominance of E. faecalis and E. faecium (77\%), as well as the clinical significance of these two species, they were the exclusive focus during two subsequent years. From these two species, E. faecalis was the most prevalent from both, sludge (78\%) and house flies (83\%), and therefore, the majority of effort was applied to characterizing this species. The prevalence of E. faecalis in this study is consistent with previous surveys of sewage $[9,51]$.

Enterococci were isolated from $94 \%$ of sludge samples from the four sites at a concentration of at least $10^{6} \mathrm{CFU} / \mathrm{g}$. This prevalence and concentration is comparable to other studies that have screened sewage for the enterococci $[2,9,19,47,51]$. Sixty six percent of house flies were positive for enterococci at a concentration $\sim 10^{3} \mathrm{CFU} / \mathrm{fly}$. This is comparable to previous surveys $[1,11,44]$, although the overall prevalence among flies is lower in this study. In other studies enterococcal prevalence in house flies occurred at rates of $90-98 \%$ in environments such as swine operations, cattle feedlots, and restaurants $[1,11,44]$ 
Of the four WWTF involved in the study, WWTF 2, 3 and 4 were similar as they received and processed only human sewage. WWTF-1 was unique in receiving industrial waste from a commercial sausage plant. Sludge sampled from this site consisted entirely of the solids (meat waste) from this source, which were not mixed with residential sewage. The abundance of fly activity, amount of meat waste, and prevalence of antibiotic resistant and potentially virulent enterococci made this location of particular interest. As such, more extensive sampling was conducted at WWTF-1 and it offered the best opportunity to test the study hypothesis. The sausage facility did not actively slaughter animals but received meat (beef, pork and poultry) to be used in the final product. Therefore, there were multiple types of meat that likely arrived from multiple sources. Consequently, enterococci from the sludge of WWTF-1 were likely of animal rather than human origin so it is appropriate to compare our findings to reports from other meat processing facilities and their products. The ratio of $E$. faecalis/E. faecium at WWTF-1 was 9:1, which is similar to other studies that have surveyed enterococci at meat processing operations (beef, pork and poultry) and from associated meat products. In most of those studies, $E$. faecalis was dominant followed by E. faecium $[14,30,36,45,49,54,58]$. In the current study, the species composition among sludge and house flies was comparable with $E$. faecalis being the most abundant species from both sources (Fig. S1).

Enterococci from WWTF-1 were more frequently antibiotic resistant than those from WWTF 2-4. The resistance was mainly detected to tetracycline and doxycycline (tetracyclines), streptomycin and gentamicin (aminoglycosides), and erythromycin (macrolide). It has been reported that the enterococcal resistance patterns from food items often reflect the use of antimicrobials in the source animal [40,64]. Each of the antimicrobial classes that enterococci in this study were commonly resistant to are used for growth promotion in food animals [64]. Tetracycline resistance has also been commonly reported among enterococci from a variety of meat products $[30,48,49,53,54]$. Erythromycin and gentamicin resistant enterococci are widespread in pork [48], beef, and chicken [37] meat products. High level resistance to aminoglycosides (streptomycin, gentamicin) is common among enterococci from food animals and associated meat products $[10,27,37]$.

There was good overall agreement among E. faecalis antibiotic resistance profiles from sludge and house flies captured onsite of the WWTF. Further, there was high concurrence between the two 
sources when considering the specific combinations of resistances. These observations are consistent with the hypothesis that the flies acquired the bacteria from the sludge.

Another noteworthy characteristic of $E$. faecalis from WWTF-1 was the prevalence of virulence factors, particularly for gelatinase (ge/E) and aggregation substance (asa1). This prevalence of putative virulence factors is common among food-animal enterococci $[46,49]$. The virulence data for $E$. faecalis are also consistent with the hypothesis that the flies acquired E. faecalis from sludge. Both genotypic and phenotypic virulence patterns were similar for each source.

Genotyping of $E$. faecalis collected in the second year from WWTF-1 did not reveal clonal matches between sludge and house flies (Fig. S2). This is likely due to the very large genotypic diversity among sludge isolates because of various sources in the meat processing plant. Due to this diversity, genotyping efforts of $E$. faecalis collected during the third year focused on only two collection dates in an effort to detect clonal matches among the respective sources. Among these isolates, three clonal matches between sludge and onsite house flies were detected. This provides a strong evidence to support the study hypothesis that flies acquired enterococci from WWTFs.

It should be noted that only one WWTF processing non-human waste (WWTF-1) was included in this study and additional sites of this type need to be investigated. Further, the microbial community in the flies prior to their exposure to WWTFs is unknown and therefore the contamination of the sludge with AR bacteria by flies cannot be ruled out. However, we expect that fly to sludge bacterial transfer was much less extensive due to the amount and abundance of sludge relative to the number of flies at WWTFs.

Eight multi-drug resistant $E$. faecalis isolates from flies were selected for in vitro conjugation assays to evaluate the potential for horizontal transfer of AR genes. Transfer of one or more resistance determinants was observed among all E. faecalis at transconjugant/donor (T/D) rates from $2.9 \times 10^{-8}$ to $7.3 \times 10^{-3}$. Enterococci are well recognized as AR gene reservoirs and readily transfer genes both intraand inter-specifically $[31,38,73]$. A number of mobile genetic elements (MGE) such as plasmids and transposons are present in enterococci which facilitate AR gene transfer [31, 73]. Further, we have demonstrated previously that the house fly digestive tract provides an environment conducive for conjugal transfer of antibiotic resistance genes among E. faecalis [3]. Horizontal gene transfer as well as clonal 
propagation in the house fly digestive tract, represent the two main ways of amplifying clinically significant enterococci and their associated resistance determinants and may lead to enhanced house fly vector competence for these bacteria.

As outlined above, numerous independent measures of $E$. faecalis from WWTF-1 support the hypothesis that house flies acquired these bacteria at the facility. The other part of the study focused on fly dispersal from WWTF-1 and dissemination of AR enterococci. Here we offer circumstantial evidence for house flies carrying enterococci from the WWTF-1 to distances up to $2 \mathrm{~km}$. Although the overall prevalence of antibiotic resistance among $E$. faecalis from offsite house flies was significantly lower, the profile of specific antibiotics that the bacteria were resistant to matched that of $E$. faecalis from both, sludge and onsite house flies. The same general trend was found among virulence genes and phenotypes. There were no clonal matches among offsite flies to either sludge or onsite flies. This is not unexpected given the high level of diversity of $E$. faecalis from sludge. Further, flies collected away from the WWTF-1 could have migrated from other areas and therefore a considerable level of dilution is expected. Finally, it is possible that enterococci acquired from the WWTF-1 have diminished in prevalence during the time it took the flies to migrate to the offsite locations.

WWTF 2- 4 received exclusively human sewage and therefore represent more typical wastewater operations. Among the three sites, E. faecalis antibiotic resistance occurred to the same five antibiotics as observed at WWTF-1 although at a lower overall prevalence. This pattern of phenotypic resistance is comparable to other studies assessing $E$. faecalis resistance from sewage $[9,19]$. No resistance to streptomycin was observed from E. faecalis at WWTF 2 and 3. This was the case among isolates from both sludge and house flies as would be expected if the sludge is a source of enterococci for flies. Further, WWTF 2 and 3 had similar resistance profiles to tetracycline, doxycycline, gentamicin and erythromycin among the two sources (sludge and flies).

It is unknown to what extent human-clinical sources of $E$. faecalis contributed to the bacteria recovered and analyzed from WWTF 2, 3 and 4 . WWTF-3 had the greatest potential for contribution from this source as it received waste from the largest hospital with a 12 bed ICU. However, it also had the largest municipal population; therefore, dilution in the sewage stream from the overall community was 
greatest. Risk assessments based on these parameters would be beneficial for predicting AR bacterial exposure and management/containment of AR gene spread.

This study assessed an environment where house flies may play a role in AR enterococcal ecology. Our data support the hypothesis that flies acquire and disseminate AR enterococci from WWTFs. The best evidence originates from WWTF-1 which apparently involved primarily a food animal source of enterococci. Though at the outset the goal of the study was to investigate a human source of AR enterococci to flies, the nature of waste processed at WWTF-1 points to yet another animal source of the AR bacteria. Despite this, our results are broadly applicable to more typical WWTFs that receive human sewage. It should be noted that while this study focused on enterococci, there are a number of other bacteria of medical/veterinary clinical importance that could be acquired and disseminated by house flies from WWTF. Examples of bacteria that have been cultured from wastewater and at various points along the waste treatment stream include multi-drug resistant Escherichia coli [22, 65, 72], Salmonella, both Typhi and non-Typhi serovars [22, 63], Acinetobacter spp. [26], Staphylococcus aureus, Legionella pneumophila, and Clostridium difficile [71].

Our results enhance understanding of risks associated with dissemination of AR bacteria. Factors such as the access of house flies to various wastewater treatment processes should be considered when operating and designing new facilities. Further, WWTF management should incorporate insect management during the peak season of fly activity to limit AR bacterial spread.

\section{Acknowledgements}

We thank Dr. Anuradha Ghosh for comments on the manuscript. This study was supported by the USDA grant for the Multi-State Research Program S1030. Funding was also provided through a grant from the Deployed War-Fighter Protection (DWFP) Research Program of the U.S. Department of Defense through the Armed Forces Pest Management Board (AFPMB). This is contribution no. 14-129-J from the Kansas Agricultural Experiment Station. 


\section{References}

1. Ahmad A, Ghosh A, Schal C, Zurek L (2011) Insects in confined swine operations carry a large antibiotic resistant and potentially virulent enterococcal community. BMC Microbiol 11:23

2. Ahmed W, Stewart J, Gardner T, Powell D (2008) A real-time polymerase chain reaction assay for quantitative detection of the human-specific enterococci surface protein marker in sewage and environmental waters. Environ Microbiol 10:3255-3264

3. Akhtar M, Hirt H, Zurek $L$ (2009) Horizontal transfer of the tetracycline resistance gene tetM mediated by pCF10 among Enterococcus faecalis in the house fly (Musca domestica L.) alimentary canal. Microb Ecol 58:509-518

4. Amachawadi RG, Shelton NW, Jacob ME, Shi X, Narayanan SK, Zurek L, Dritz SS, Nelssen JL, Tokach MD, Nagaraja TG (2010) Occurrence of tcrB, a Transferable Copper Resistance Gene, in Fecal Enterococci of Swine. Foodborne Pathogens and Disease 7:1089-1097

5. Amyes SG (2007) Enterococci and streptococci. Int J Antimicrob Agents 29 Suppl 3:S43-52

6. Arias CA, Murray BE (2009) Antibiotic-resistant bugs in the 21st century--a clinical super-challenge. $\mathrm{N}$ Engl J Med 360:439-443

7. Arthurson V (2008) Proper sanitization of sewage sludge: a critical issue for a sustainable society. Appl Environ Microbiol 74:5267-5275

8. Beier RC, Duke SE, Ziprin RL, Harvey RB, Hume ME, Poole TL, Scott HM, Highfield LD, Alali WQ, Andrews K, Anderson RC, Nisbet DJ (2008) Antibiotic and disinfectant susceptibility profiles of vancomycin-resistant Enterococcus faecium (VRE) isolated from community wastewater in Texas. Bull Environ Contam Toxicol 80:188-194

9. Blanch AR, Caplin JL, Iversen A, Kuhn I, Manero A, Taylor HD, Vilanova X (2003) Comparison of enterococcal populations related to urban and hospital wastewater in various climatic and geographic European regions. J Appl Microbiol 94:994-1002

10. Butaye P, Van Damme K, Devriese LA, Van Damme L, Bael M, Lauwers S, Haesebrouck F (2000) In vitro susceptibility of Enterococcus faecium isolated from food to growth-promoting and therapeutic antibiotics. Int J Food Microbiol 54:181-187

11. Chakrabarti S, Kambhampati S, Zurek $L$ (2010) Assessment of house fly dispersal between rural and urban habitats in kansas, USA. J Kans Entomol Soc 83:172-188

12. Cheremisinoff NP (1996) Biotechnology for waste and wastewater treatment, Noyes Publications, Westwood, NJ

13. Clinical and Laboratory Standards Institute (2010) Performance standards for antimicrobial susceptibility testing; twentieth informational supplement. CLSI Document M100-S20. WaynePa: Clinical and Laboratory Standards Institute 30:76-79

14. Devriese LA, Pot B, Van Damme L, Kersters K, Haesebrouck F (1995) Identification of Enterococcus species isolated from foods of animal origin. Int J Food Microbiol 26:187-197 
15. Dohoo IR, Martin SW, Stryhn H (2009) Mixed models for discrete data. In: Anonymous Veterinary Epidemiologic Research, VER Inc, Charlottetown, PEI, Canada, pp 579-606

16. Dunny GM, Craig RA, Carron RL, Clewell DB (1979) Plasmid Transfer in Streptococcus faecalis Production of Multiple Sex-Pheromones by Recipients. Plasmid 2:454-465

17. Dunny GM, Brown BL, Clewell DB (1978) Induced cell aggregation and mating in Streptococcus faecalis: evidence for a bacterial sex pheromone. Proc Natl Acad Sci U S A 75:3479 -3483

18. Elsayed S, Hamilton N, Boyd D, Mulvey M (2001) Improved primer design for multiplex PCR analysis of vancomycin-resistant Enterococcus spp. J Clin Microbiol 39:2367

19. Ferreira da Silva M, Tiago I, Verissimo A, Boaventura RA, Nunes OC, Manaia CM (2006) Antibiotic resistance of enterococci and related bacteria in an urban wastewater treatment plant. FEMS Microbiol Ecol 55:322-329

20. Fisher K, Phillips C (2009) The ecology, epidemiology and virulence of Enterococcus. Microbiology 155:1749-1757

21. French GL (1998) Enterococci and vancomycin resistance. Clinical Infectious Diseases 27:S75-S83

22. Grabow WOK, Prozesky OW (1973) Drug-resistance of coliform bacteria in hospital and city sewage. Antimicrob Agents Chemother 3:175-180

23. Graczyk TK, Knight R, Gilman RH, Cranfield MR (2001) The role of non-biting flies in the epidemiology of human infectious diseases. Microbes Infect 3:231-235

24. Graham JP, Price LB, Evans SL, Graczyk TK, Silbergeld EK (2009) Antibiotic resistant enterococci and staphylococci isolated from flies collected near confined poultry feeding operations. Sci Total Environ 407:2701-2710

25. Greenberg B (1965) Flies and Disease. Sci Am 213:92-99

26. Guardabassi L, Petersen A, Olsen JE, Dalsgaard A (1998) Antibiotic resistance in Acinetobacter spp. isolated from sewers receiving waste effluent from a hospital and a pharmaceutical plant. Appl Environ Microbiol 64:3499-3502

27. Hammerum AM, Lester $\mathrm{CH}$, Heuer OE (2010) Antimicrobial-resistant enterococci in animals and meat: A human health hazard? Foodborne Pathog Dis 7:1137-1146

28. Harwood VJ, Brownell M, Perusek W, Whitlock JE (2001) Vancomycin-resistant Enterococcus spp. isolated from wastewater and chicken feces in the United States. Appl Environ Microbiol 67:49304933

29. Hawkey PM (2008) The growing burden of antimicrobial resistance. J Antimicrob Chemother 62 Suppl 1:i1-9

30. Hayes JR, English LL, Carter PJ, Proescholdt T, Lee KY, Wagner DD, White DG (2003) Prevalence and antimicrobial resistance of enterococcus species isolated from retail meats. Appl Environ Microbiol 69:7153-7160 
31. Hegstad K, Mikalsen T, Coque TM, Werner G, Sundsfjord A (2010) Mobile genetic elements and their contribution to the emergence of antimicrobial resistant Enterococcus faecalis and Enterococcus faecium. Clinical Microbiology and Infection 16:541-554

32. Hidron A, I., Edwards JR, Patel J (2008) Antimicrobial-resistant pathogens associated with healthcare-associated infections: annual summary of data reported to the National Healthcare Safety Network at the Centers for Disease Control and Prevention, 2006-2007 (vol 29, pg 996, 2008). Infection Control and Hospital Epidemiology 29:996-1011

33. Horan NJ (1990) Biological wastewater treatment systems, John Wiley \& Sons, New York

34. Huycke MM, Sahm DF, Gilmore MS (1998) Multiple-drug resistant enterococci: the nature of the problem and an agenda for the future. Emerg Infect Dis 4:239-249

35. Kariyama R, Mitsuhata R, Chow JW, Clewell DB, Kumon H (2000) Simple and reliable multiplex PCR assay for surveillance isolates of vancomycin-resistant enterococci. J Clin Microbiol 38:30923095

36. Knudston LM, Hartman PA (1993) Enterococci in pork processing. J Food Prot 56:6-9

37. Koluman A, Akan LS, Cakiroglu FP (2009) Occurrence and antimicrobial resistance of enterococci in retail foods. Food Control 20:281-283

38. Kotzamanidis C, Zdragas A, Kourelis A, Moraitou E, Papa A, Yiantzi V, Pantelidou C, Yiangou M (2009) Characterization of vanA-type Enterococcus faecium isolates from urban and hospital wastewater and pigs. J Appl Microbiol 107:997-1005

39. Levy SB, Marshall B (2004) Antibacterial resistance worldwide: causes, challenges and responses. Nat Med 10:S122-S129

40. Lukasova J, Sustackova A (2003) Enterococci and antibiotic resistance. Acta Veterinaria Brno 72:315-323

41. Macovei L, Ghosh A, Thomas VC, Hancock LE, Mahmood S, Zurek L (2009) Enterococcus faecalis with the gelatinase phenotype regulated by the fsr operon and with biofilm-forming capacity are common in the agricultural environment. Environ Microbiol 11:1540-1547

42. Macovei L, Miles B, Zurek $L$ (2008) Potential of houseflies to contaminate ready-to-eat food with antibiotic-resistant enterococci. J Food Prot 71:435-439

43. Macovei L, Zurek L (2007) Influx of enterococci and associated antibiotic resistance and virulence genes from ready-to-eat food to the human digestive tract. Appl Environ Microbiol 73:6740-6747

44. Macovei L, Zurek L (2006) Ecology of antibiotic resistance genes: characterization of enterococci from houseflies collected in food settings. Appl Environ Microbiol 72:4028-4035

45. Martin B, Corominas L, Garriga M, Aymerich T (2008) Identification and tracing of Enterococcus spp. by RAPD-PCR in traditional fermented sausages and meat environment. J Appl Microbiol 106:66-77

46. Martin B, Garriga M, Hugas M, Aymerich T (2005) Genetic diversity and safety aspects of enterococci from slightly fermented sausages. J Appl Microbiol 98:1177-1190 
47. Martins da Costa P, Vaz-Pires P, Bernardo F (2006) Antimicrobial resistance in Enterococcus spp. isolated in inflow, effluent and sludge from municipal sewage water treatment plants. Water Res 40:1393-1403

48. McGowan LL, Jackson CR, Barrett JB, Hiott LM, Fedorka-Cray PJ (2006) Prevalence and antimicrobial resistance of enterococci isolated from retail fruits, vegetables, and meats. J Food Prot 69:2976-2982

49. McGowan-Spicer LL, Fedorka-Cray PJ, Frye JG, Meinersmann RJ, Barrett JB, Jackson CR (2008) Antimicrobial resistance and virulence of Enterococcus faecalis isolated from retail food. J Food Prot 71:760-769

50. Murray BE, Singh KV, Heath JD, Sharma BR, Weinstock GM (1990) Comparison of Genomic Dnas of Different Enterococcal Isolates using Restriction Endonucleases with Infrequent Recognition Sites. J Clin Microbiol 28:2059-2063

51. Nagulapally SR, Ahmad A, Henry A, Marchin GL, Zurek L, Bhandari A (2009) Occurrence of ciprofloxacin, trimethoprim sulfamethoxazole, and vancomycin-resistant bacteria in a municipal wastewater treatment plant. Water Environ Res 81:82-90

52. North East Biosolids and Residuals Association (NEBRA) (2007) A National Biosolids Regulation, Quality, End Use \& Disposal Survey.

53. Ogier JC, Serror P (2008) Safety assessment of dairy microorganisms: the Enterococcus genus. Int J Food Microbiol 126:291-301

54. Peters J, Mac K, Wichmann-Schauer H, Klein G, Ellerbroek L (2003) Species distribution and antibiotic resistance patterns of enterococci isolated from food of animal origin in Germany. Int $\mathrm{J}$ Food Microbiol 88:311-314

55. Poole TL, Hume ME, Campbell LD, Scott HM, Alali WQ, Harvey RB (2005) Vancomycin-resistant Enterococcus faecium strains isolated from community wastewater from a semiclosed agri-food system in Texas. Antimicrob Agents Chemother 49:4382-4385

56. Poyart C, Quesnes G, Trieu-Cuot P (2000) Sequencing the gene encoding manganese-dependent superoxide dismutase for rapid species identification of enterococci. J Clin Microbiol 38:415-418

57. Qadri SMH, Flournoy DJ, Qadri SGM (1987) Sodium chloride esculin hydrolysis test for rapid identification of enterococci. J Clin Microbiol 25:1107-1108

58. Quednau M, Ahrne S, Petersson AC, Molin G (1998) Identification of clinically important species of Enterococcus within 1 day with randomly amplified polymorphic DNA (RAPD). Curr Microbiol $36: 332-336$

59. Reik R, Tenover FC, Klein E, McDonald LC (2008) The burden of vancomycin-resistant enterococcal infections in US hospitals, 2003 to 2004. Diagn Microbiol Infect Dis 62:81-85

60. Reinthaler FF, Posch J, Feierl G, Wust G, Haas D, Ruckenbauer G, Mascher F, Marth E (2003) Antibiotic resistance of $E$. coli in sewage and sludge. Water Res 37:1685-1690

61. Rice LB (2006) Antimicrobial resistance in gram-positive bacteria. Am J Infect Control 34:S11-S19 
62. Schleifer KH, Kilpperbalz R (1984) Transfer of Streptococcus faecalis and Streptococcus faecium to the genus Enterococcus nom rev as Enterococcus faecalis comb nov and Enterococcus faecium Comb-Nov. Int J Syst Bacteriol 34:31-34

63. Schluter A, Szczepanowski R, Puhler A, Top EM (2007) Genomics of IncP-1 antibiotic resistance plasmids isolated from wastewater treatment plants provides evidence for a widely accessible drug resistance gene pool. FEMS Microbiol Rev 31:449-477

64. Silbergeld EK, Graham J, Price LB (2008) Industrial food animal production, antimicrobial resistance, and human health. Annu Rev Public Health 29:151-169

65. Sturtevant AB,Jr, Feary TW (1969) Incidence of infectious drug resistance among lactose-fermenting bacteria isolated from raw and treated sewage. Appl Microbiol 18:918-924

66. Sung JM, Lindsay JA (2007) Staphylococcus aureus strains that are hypersusceptible to resistance gene transfer from enterococci. Antimicrob Agents Chemother 51:2189-2191

67. Tendolkar PM, Baghdayan AS, Shankar N (2006) Putative surface proteins encoded within a novel transferable locus confer a high-biofilm phenotype to Enterococcus faecalis. J Bacteriol 188:20632072

68. Top J, Willems R, Blok H, de Regt M, Jalink K, Troelstra A, Goorhuis B, Bonten M (2007) Ecological replacement of Enterococcus faecalis by multiresistant clonal complex 17 Enterococcus faecium. Clinical Microbiology and Infection 13:316-319

69. Vankerckhoven V, Van Autgaerden T, Vael C, Lammens C, Chapelle S, Rossi R, Jabes D, Goossens H (2004) Development of a multiplex PCR for the detection of asa1, gelE, cylA, esp, and hyl genes in enterococci and survey for virulence determinants among European hospital isolates of Enterococcus faecium. J Clin Microbiol 42:4473-4479

70. Vermunt JK (2005) Mixed-effects logistic regression models for indirectly observed discrete outcome variables. Multivariate Behavioral Research 40:281-301

71. Viau E, Peccia J (2009) Survey of wastewater indicators and human pathogen genomes in biosolids produced by class a and class B stabilization treatments. Appl Environ Microbiol 75:164-174

72. Walter MV, Vennes JW (1985) Occurrence of multiple-antibiotic-resistant enteric bacteria in domestic sewage and oxidation lagoons. Appl Environ Microbiol 50:930-933

73. Weaver KE, Rice LB, Churchward G (2002) Plasmids and transposons. In: Gilmore MS (ed) The enterococci: pathogenesis, molecular biology, and antibiotic resistance, ASM Press, Washington, DC, pp 219-263

74. Zurek L, Schal C, Watson DW (2000) Diversity and contribution of the intestinal bacterial community to the development of Musca domestica (Diptera: Muscidae) larvae. J Med Entomol 37:924-928 
Table 1. Prevalence of Enterococcus faecalis and E. faecium from sludge and house flies (HF) at four wastewater treatment facilities (WWTF).

\section{Sludge}

\begin{tabular}{|c|c|c|c|c|c|}
\hline \multirow[t]{2}{*}{ WWTF } & \multirow{2}{*}{$\begin{array}{l}\text { No. of samples } \\
\text { analyzed/ } \\
\text { no. positive }(\%)\end{array}$} & \multirow{2}{*}{$\begin{array}{c}\mathrm{CFU} / \mathrm{g} \text { or HF} \\
(\text { mean } \pm \mathrm{SEM})\end{array}$} & \multirow{2}{*}{$\begin{array}{c}\text { Total no. of isolates } \\
\text { characterized }\end{array}$} & \multicolumn{2}{|c|}{ No. (\%) of isolates } \\
\hline & & & & E. faecalis & E. faecium \\
\hline 1 & $41 / 39(95.1)$ & $4.9 \pm 1.5 \times 10^{6}$ & 100 & $88(88.0)$ & $12(12.0)$ \\
\hline 2 & $15 / 13(86.7)$ & $2.6 \pm 1.7 \times 10^{5}$ & 37 & $31(83.8)$ & $6(16.2)$ \\
\hline 3 & $14 / 14(100)$ & $5.5 \pm 2.6 \times 10^{4}$ & 37 & $29(78.3)$ & $8(21.6)$ \\
\hline 4 & $19 / 18(94.7)$ & $2.5 \pm 0.6 \times 10^{4}$ & 32 & $13(40.6)$ & $19(59.4)$ \\
\hline Total or mean & $89 / 84(94.4)$ & $2.3 \pm 0.8 \times 10^{6}$ & 206 & $161(78.2)$ & $45(21.8)$ \\
\hline \multicolumn{6}{|c|}{ House flies } \\
\hline 1 & $83 / 56(67.5)$ & $4.5 \pm 1.0 \times 10^{3}$ & 124 & $120(96.8)$ & $4(3.2)$ \\
\hline Offsite 1 & $84 / 51(60.7)$ & $1.5 \pm 1.0 \times 10^{4}$ & 130 & $98(75.4)$ & $32(24.6)$ \\
\hline 2 & $28 / 16(57.1)$ & $3.7 \pm 1.8 \times 10^{3}$ & 25 & $19(76.0)$ & $6(24.0)$ \\
\hline 3 & $43 / 30(69.8)$ & $1.3 \pm 1.1 \times 10^{4}$ & 34 & $26(76.4)$ & $8(23.5)$ \\
\hline 4 & $38 / 28(73.7)$ & $7.0 \pm 2.0 \times 10^{3}$ & 43 & $33(76.8)$ & $10(23.2)$ \\
\hline Total or mean & $276 / 181(65.6)$ & $8.9 \pm 3.4 \times 10^{3}$ & 356 & $296(83.1)$ & $60(16.9)$ \\
\hline
\end{tabular}


Figure 1. Resistance profiles of E. faecalis to 11 antibiotics from sludge and house flies (HF) at four wastewater treatment facilities (WWTF) and HF from nearby (offsite) of WWTF-1.

WWTF-1 resistance profile is contrasted with the combined profiles of WWTF 2, 3, and 4. A isolates from WWTF-1, B - combined isolates from WWTF 2, 3, 4. TET-tetracycline, Ddoxycyline, S-streptomycin, GM-gentamicin, ERY-erythromycin, AMP-ampicillin, CIPciprofloxacin, VAN-vancomycin, NIT-nitrofurantoin, LZO-linezolid, TGC-tigecycline.

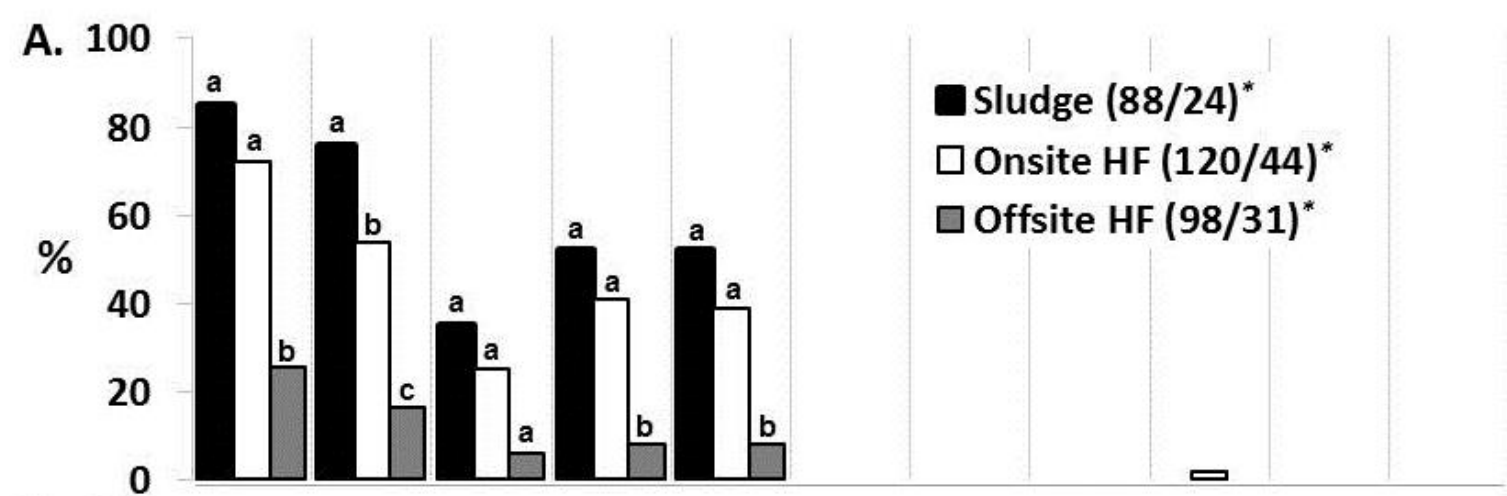

B. 100

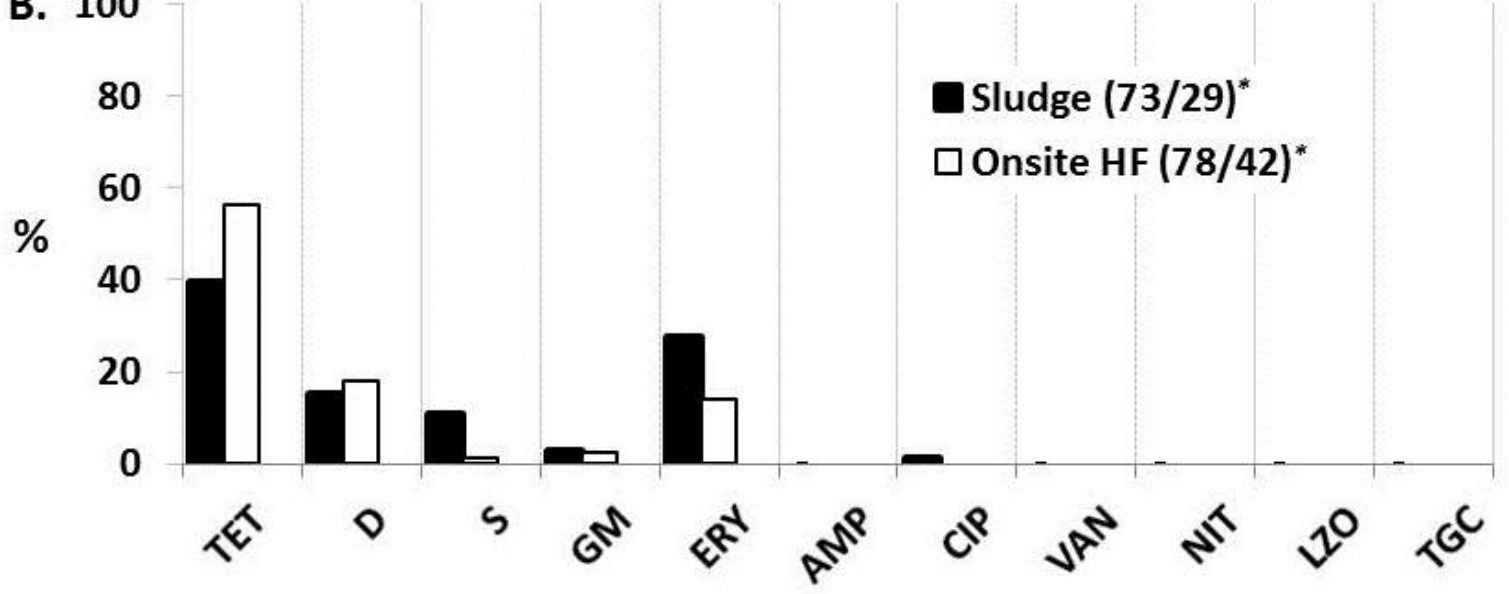

* number of E. faecalis isolates/number of samples 
Table 2. Antibiotic resistance profile among E. faecalis from sludge and house flies (HF) onsite and nearby (offsite) of WWTF-1. TET-tetracycline, D-doxycyline, ERY-erythromycin, S-streptomycin, GM-gentamicin, NIT- nitrofuratoin.

\begin{tabular}{|c|c|c|c|}
\hline \multirow[t]{2}{*}{ Resistance profile } & Sludge $(n=88 / 24) *$ & HF onsite $(n=120 / 44) *$ & HF offsite $(n=98 / 31) *$ \\
\hline & no. of resistant isolates $(\%)$ & no. of resistant isolates $(\%)$ & no. of resistant isolates $(\%)$ \\
\hline TET & $6(6.8)$ & $11(9.2)$ & $7(7.1)$ \\
\hline ERY & $3(3.4)$ & $2(1.6)$ & \\
\hline GM & & & $5(5.1)$ \\
\hline D & $1(1.1)$ & & \\
\hline TET, D & $11(12.5)$ & $11(9.2)$ & $6(6.1)$ \\
\hline TET, $S$ & $2(2.3)$ & $2(1.6)$ & \\
\hline TET, ERY & & $5(4.2)$ & \\
\hline TET, D, GM & $14(15.9)$ & $15(12.5)$ & $1(1.0)$ \\
\hline TET, D, ERY & $6(6.8)$ & $6(5.0)$ & $4(4.1)$ \\
\hline TET, ERY, S & $3(3.4)$ & & $2(2.0)$ \\
\hline TET, ERY, NIT & & $1(\overline{0.8})$ & \\
\hline TET, D, $\mathrm{S}$ & $1(1.1)$ & & $1(1.0)$ \\
\hline D, ERY, GM & $1(1.1)$ & & \\
\hline TET, D, ERY, GM & $8(9.1)$ & $6(\overline{5.0})$ & \\
\hline TET, D, ERY, S & $2(2.3)$ & $1(0.8)$ & \\
\hline TET, ERY, S, GM & & $2(1.6)$ & \\
\hline TET, D, S, GM & & $1(0.8)$ & \\
\hline TET, D, GM, NIT & & $1(0.8)$ & \\
\hline TET, D, ERY, S, GM & $22(25.0)$ & $24(20.0)$ & $1(1.0)$ \\
\hline Pan-susceptible & $8(9.1)$ & $32(26.7)$ & $71(72.5)$ \\
\hline
\end{tabular}

* number of E. faecalis/number of samples 
Table 3. Horizontal transfer of antibiotic resistance traits by broth and filter mating among E. faecalis from house flies at and near WWTF-1. Recipient for streptomycin E. faecalis 41-31 (wild isolate), recipient for all other resistance genes E. faecalis OG1SSP. OFHF, offsite house fly; ONHF, onsite house fly.

\begin{tabular}{|c|c|c|c|c|c|}
\hline \multirow[t]{2}{*}{ Donor } & \multicolumn{5}{|c|}{ Broth mating transfer rate (T/D)* } \\
\hline & streptomycin & gentamicin & tetracycline & doxycycline & erythromycin \\
\hline OFHF 7-2 & 0 & $\mathrm{NR}^{a}$ & 0 & 0 & $\mathrm{NR}^{a}$ \\
\hline OFHF 7-3 & $1.7 \times 10^{-3}$ & $\mathrm{NR}^{a}$ & 0 & 0 & 0 \\
\hline OFHF 7-4 & $5.5 \times 10^{-3}$ & $\mathrm{NR}^{a}$ & 0 & $3.6 \times 10^{-7}$ & $2.9 \times 10^{-8}$ \\
\hline ONHF 5-4 & $1.1 \times 10^{-6}$ & 0 & $6.3 \times 10^{-8}$ & 0 & 0 \\
\hline ONHF 6-1 & 0 & 0 & 0 & 0 & 0 \\
\hline ONHF 8-3 & $1.9 \times 10^{-6}$ & $2.9 \times 10^{-5}$ & $6.8 \times 10^{-6}$ & $1.3 \times 10^{-6}$ & $1.8 \times 10^{-6}$ \\
\hline ONHF $10-1$ & 0 & $2.9 \times 10^{-5}$ & $3.4 \times 10^{-4}$ & $3.4 \times 10^{-4}$ & $1.4 \times 10^{-4}$ \\
\hline \multirow[t]{2}{*}{ ONHF $16-4$} & $1.5 \times 10^{-4}$ & $7.1 \times 10^{-5}$ & $8.2 \times 10^{-6}$ & $8.2 \times 10^{-6}$ & 0 \\
\hline & \multicolumn{5}{|c|}{ Filter mating transfer rate (T/D)* } \\
\hline OFHF 7-2 & 0 & $\mathrm{NR}^{a}$ & $9.3 \times 10^{-8}$ & $5.3 \times 10^{-7}$ & $\mathrm{NR}^{a}$ \\
\hline OFHF 7-3 & 0 & $\mathrm{NR}^{a}$ & 0 & $1.8 \times 10^{-7}$ & $3.9 \times 10^{-7}$ \\
\hline OFHF 7-4 & 0 & $\mathrm{NR}^{a}$ & 0 & $3.5 \times 10^{-6}$ & $1.1 \times 10^{-7}$ \\
\hline ONHF 5-4 & $1.4 \times 10^{-7}$ & $2.7 \times 10^{-7}$ & $1.1 \times 10^{-7}$ & $1.2 \times 10^{-7}$ & 0 \\
\hline ONHF 6-1 & 0 & $3.1 \times 10^{-7}$ & $1.4 \times 10^{-7}$ & $8.5 \times 10^{-8}$ & 0 \\
\hline ONHF 8-3 & 0 & $3.3 \times 10^{-3}$ & $9.1 \times 10^{-4}$ & $4.9 \times 10^{-3}$ & $2.2 \times 10^{-3}$ \\
\hline ONHF $10-1$ & $1.1 \times 10^{-6}$ & $2.1 \times 10^{-3}$ & $3.1 \times 10^{-4}$ & $7.3 \times 10^{-3}$ & $1.2 \times 10^{-3}$ \\
\hline ONHF $16-4$ & 0 & $1.3 \times 10^{-4}$ & $4.6 \times 10^{-6}$ & $1.8 \times 10^{-5}$ & $6.9 \times 10^{-7}$ \\
\hline
\end{tabular}

* T, transconjugant; D, donor

${ }^{a} \mathrm{NR}$, not resistant. Donor isolate was not phenotypically resistant to the antibiotic, therefore no transconjugate assay was performed 
Table 4. Prevalence of virulence genes and correlation to the corresponding phenotype (excluding esp phenotype) among E. faecalis from WWTF-1. gelE - gelatinase, asal - aggregation substance, cylA - cytolysin, esp - enterococcal surface protein, SG - strong gelatinase phenotype, $\mathrm{WG}$ - weak gelatinase phenotype, $\mathrm{CP}$ - clumping phenotype

\begin{tabular}{|c|c|c|c|c|}
\hline \multicolumn{5}{|c|}{ Genotype } \\
\hline Source & gelE & asal & cylA & esp \\
\hline Sludge $(88 / 24)^{*}$ & $84(95.5)^{\wedge}$ & $60(68.2)$ & $17(19.2)$ & $2(2.3)$ \\
\hline Onsite HF (120/44) & $112(93.3)$ & $60(50.0)$ & $8(6.7)$ & $1(0.8)$ \\
\hline Offsite HF (98/31) & $92(93.8)$ & $36(36.7)$ & $10(10.2)$ & $15(15.3)$ \\
\hline \multicolumn{5}{|c|}{ Phenotype } \\
\hline & \multicolumn{2}{|c|}{ gelatinase } & aggregation substance & cytolysin \\
\hline & SG & WG & $\mathrm{CP}^{\#}$ & $\beta$-hemolysis \\
\hline Sludge & $77(87.5)$ & $7(8.0)$ & 7 (11.7) & $1(1.1)$ \\
\hline Onsite HF & $103(85.8)$ & $12(10.0)$ & $6(10.0)$ & $1(0.8)$ \\
\hline Offsite HF & $76(77.5)$ & $12(12.2)$ & $1(2.8)$ & $3(3.1)$ \\
\hline
\end{tabular}

* number of isolates/number of samples

$\wedge$ number of positive isolates $(\%)$

\# only isolates positive for the asal gene were analyzed 
Figure 2. Pulsed-field gel electrophoresis (PFGE) dendogram based on Apal restriction of E. faecalis from sludge, house flies (HF) onsite and house flies offsite (RV park and apartments) from WWTF-1 collected during season 3. Frames denote clonal matches between isolates from sludge and onsite house flies.

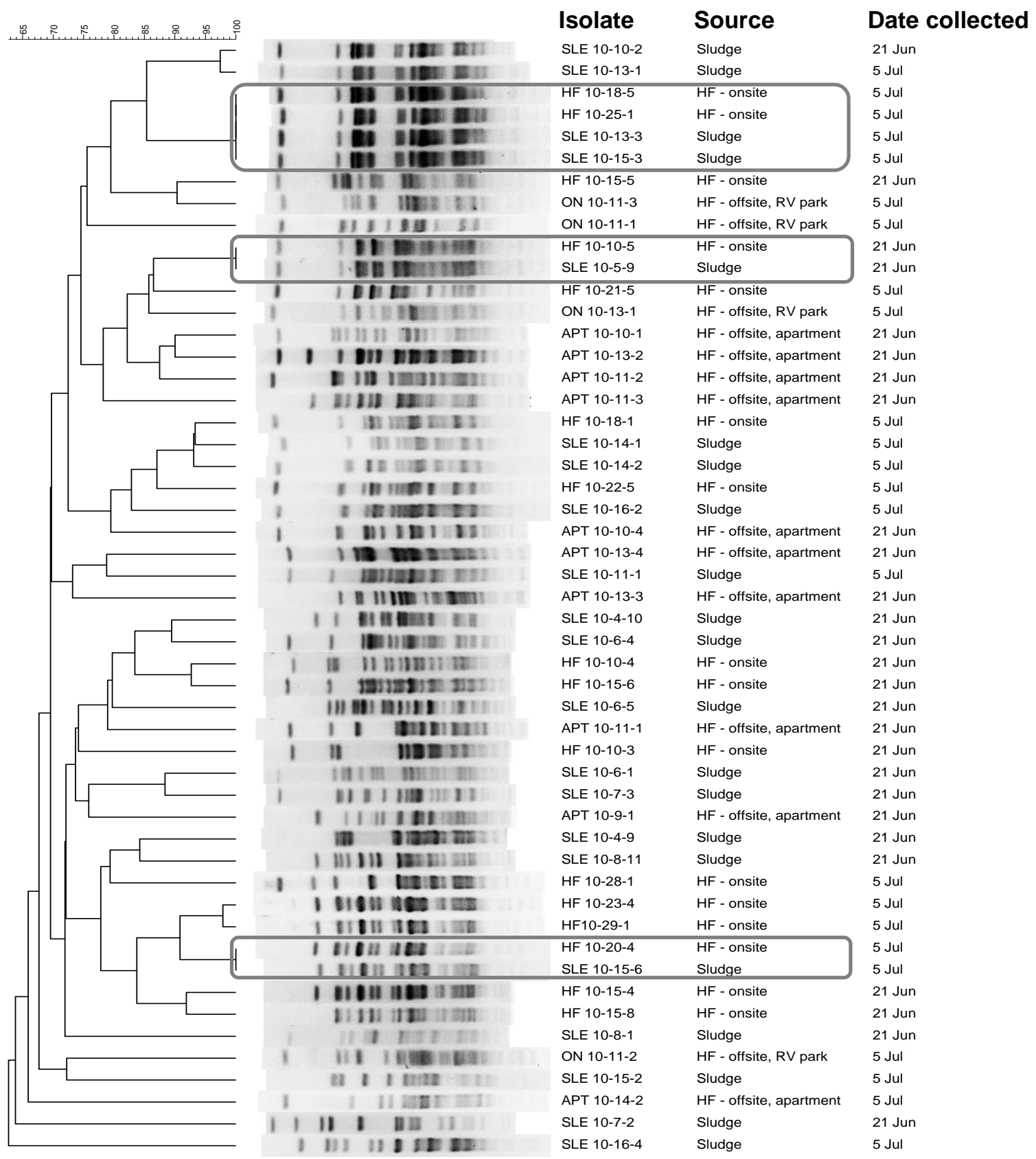




\section{Supplementary Figures}

Figure S1. Diversity of enterococci at four wastewater treatment facilities (all enterococcal isolates identified to species during the year 1). A - isolates from WWTF- 1, B - combined isolates from WWTF 2-4, HF - house flies.
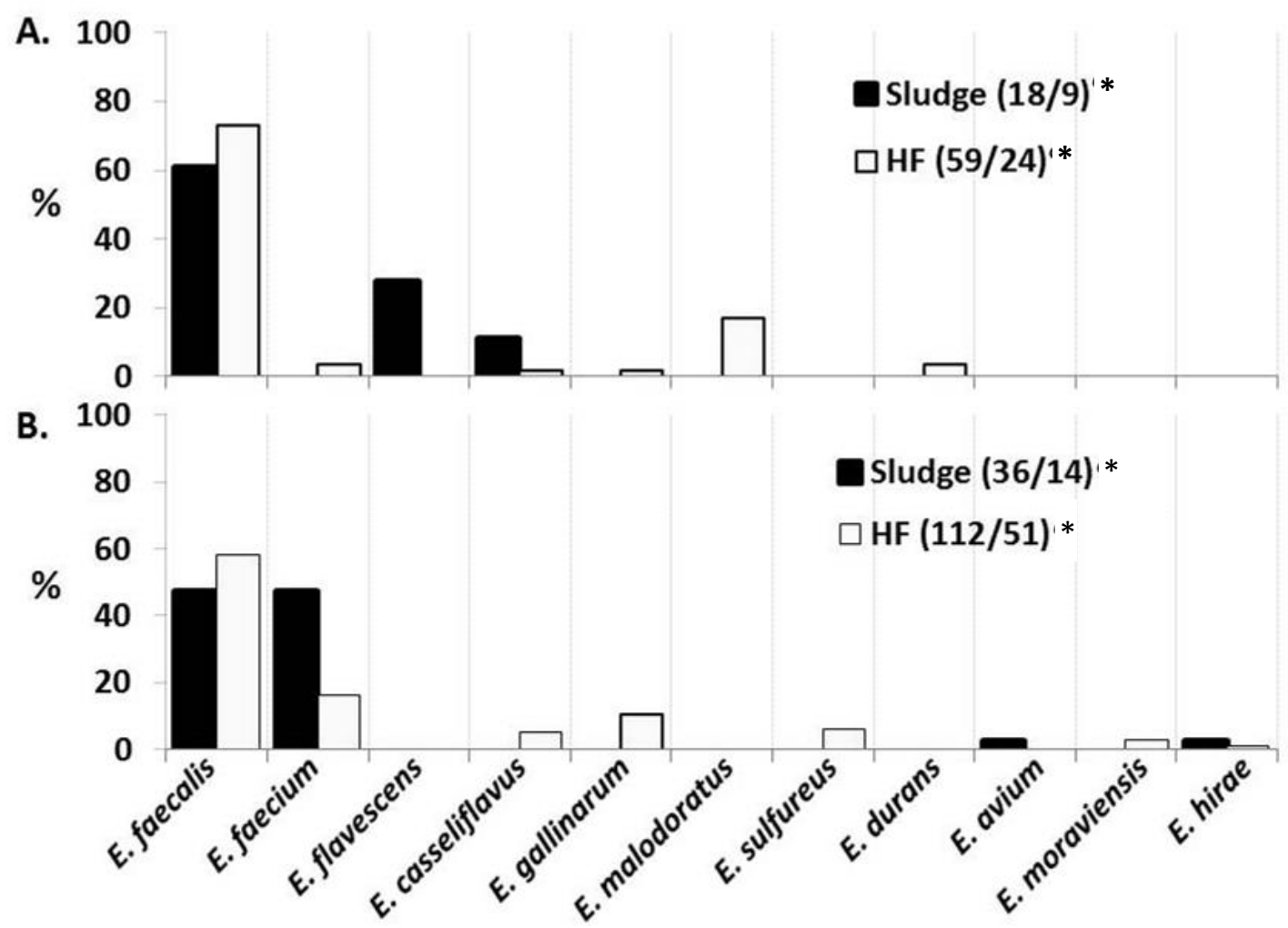

* number of enterococcal isolates/number of samples 
Figure S2. Pulsed-field gel electrophoresis (PFGE) dendogram of E. faecalis based on Apal restriction from sludge, house flies (HF) onsite and HF offsite (restaurant and apartments) of WWTF-1 collected during the season 2.
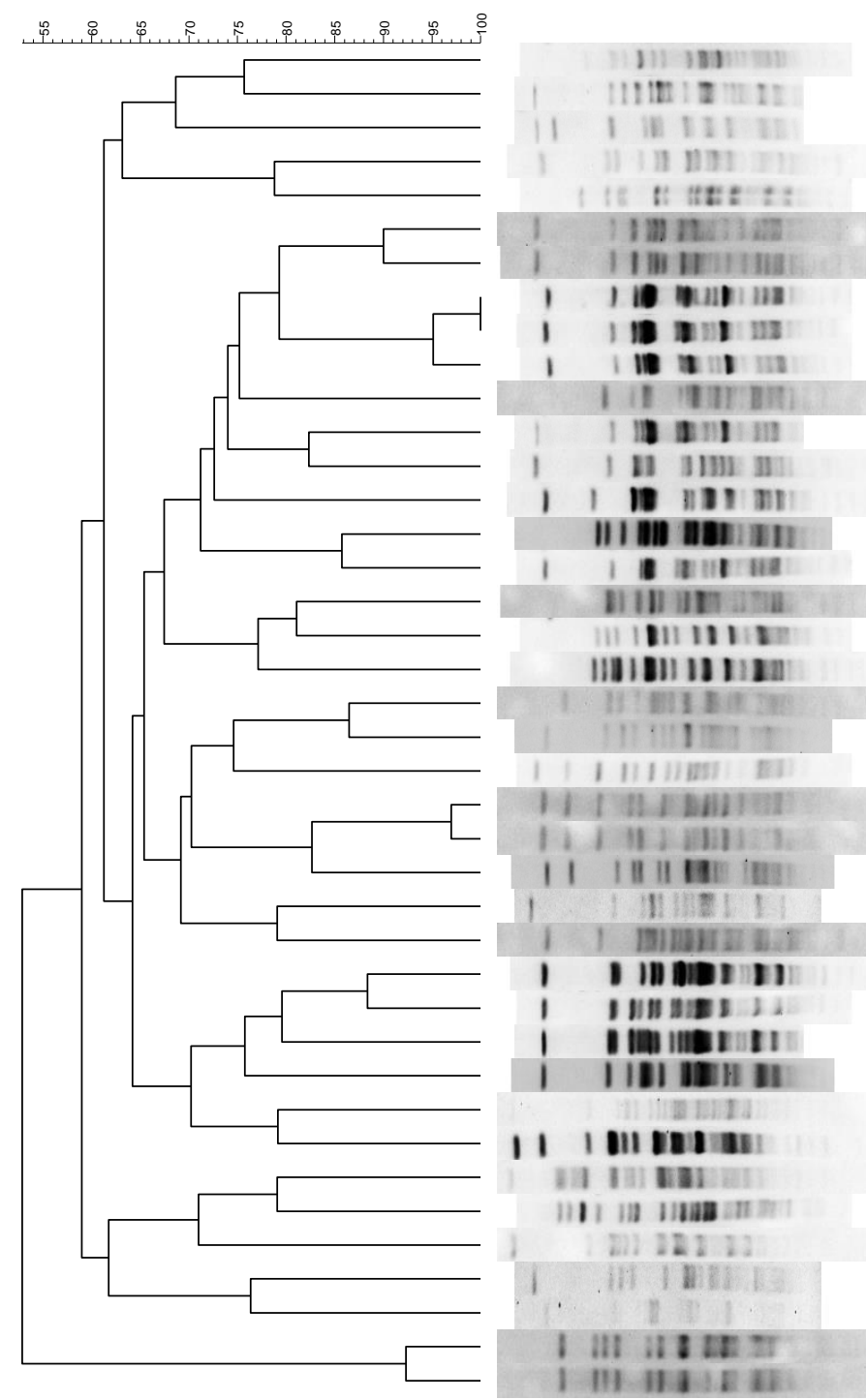

Isolate
SLE 2-6
SLE 3-3
SLE 4-3
HF 2-3
SLE 1-2
HF 16-5
HF 6-1
SLE 3-2
SLE 4-6
SLE 2-3
RI 13-1
HF 10-7
HF 6-4
HF 5-8
RO 6-3
SLE 5-2
HF 10-2
SLE 1-4
HF 10-3
APT 7-1
RO 9-7
SLE 6-5
SLE 10-5
SLE 10-7
RI 6-4
HF 17-4
HF 17-5
HF 6-2
SLE 5-5
HF 11-4
RI 8-7
HF 5-2
RO 3-4
APT 7-2
SLE 6-2
APT 9-4
HF 16-3
RI 14-4
SLE 9-3
SLE 9-7

\begin{tabular}{l} 
Source \\
Sludge \\
Sludge \\
Sludge \\
HF - onsite \\
Sludge \\
HF - onsite \\
HF - onsite \\
Sludge \\
Sludge \\
Sludge \\
HF - offsite, restaraunt \\
HF - onsite \\
HF - onsite \\
HF - onsite \\
HF - offsite, restaraunt \\
Sludge \\
HF - onsite \\
Sludge \\
HF - onsite \\
HF - offsite, apartment \\
HF - offsite, restaraunt \\
Sludge \\
Sludge \\
Sludge \\
HF - offsite, restaraunt \\
HF - onsite \\
HF - onsite \\
HF - onsite \\
Sludge \\
HF - onsite \\
HF - offsite, restaraunt \\
HF - onsite \\
HF - offsite, restaraunt \\
HF - offsite, apartment \\
Sludge \\
HF - offsite, apartment \\
HF - onsite \\
HF - offsite, restaraunt \\
Sludge \\
Sludge \\
\hline
\end{tabular}

Date collected

$01 \mathrm{Jul}$

$01 \mathrm{Jul}$

$07 \mathrm{Jul}$

24 Jun

24 Jun

$14 \mathrm{Jul}$

$01 \mathrm{Jul}$

$01 \mathrm{Jul}$

$07 \mathrm{Jul}$

$01 \mathrm{Jul}$

$20 \mathrm{Jul}$

$07 \mathrm{Jul}$

$01 \mathrm{Jul}$

$01 \mathrm{Jul}$

14 Jul

$07 \mathrm{Jul}$

$07 \mathrm{Jul}$

24 Jun

$07 \mathrm{Jul}$

$20 \mathrm{Jul}$

$15 \mathrm{Jul}$

$20 \mathrm{Jul}$

11 Aug

11 Aug

$14 \mathrm{Jul}$

$14 \mathrm{Jul}$

$14 \mathrm{Jul}$

$01 \mathrm{Jul}$

$07 \mathrm{Jul}$

$07 \mathrm{Jul}$

$15 \mathrm{Jul}$

$01 \mathrm{Jul}$

$08 \mathrm{Jul}$

$20 \mathrm{Jul}$

$20 \mathrm{Jul}$

$20 \mathrm{Jul}$

$14 \mathrm{Jul}$

$21 \mathrm{Jul}$

11 Aug

11 Aug 